\title{
DISCUSSIONS
}

\section{Effect of bacteria on soil structures}

\author{
MACLEAN, P. A. \& SMART, P. (1978). Géotechnique 28, No. 1, 122-123.
}

\section{O. B. Andersland and A. A. Nasif, Michigan State University}

The Authors are to be commended for directing attention to the effect bacteria have on soil structures. The importance of these effects in organic soils may not be full realized by many engineers. Some additional data are offered in Fig. 1 on how the coefficient of consolidation may change during decomposition of a model organic soil prepared from kaolinite and cellulose fibres. Decomposition under anaerobic conditions in the mesophilic temperature range $\left(T=38^{\circ} \mathrm{C}\right)$ was initiated by the introduction of seed bacteria and nutrients. Organic contents were measured using the ignition test coupled with a numerical analysis giving results accurate to about $\pm 1 \%$. A photograph (Fig. 2) taken with the help of an electron scanning microscope shows kaolinite particles on the fibre surface after partial decomposition.

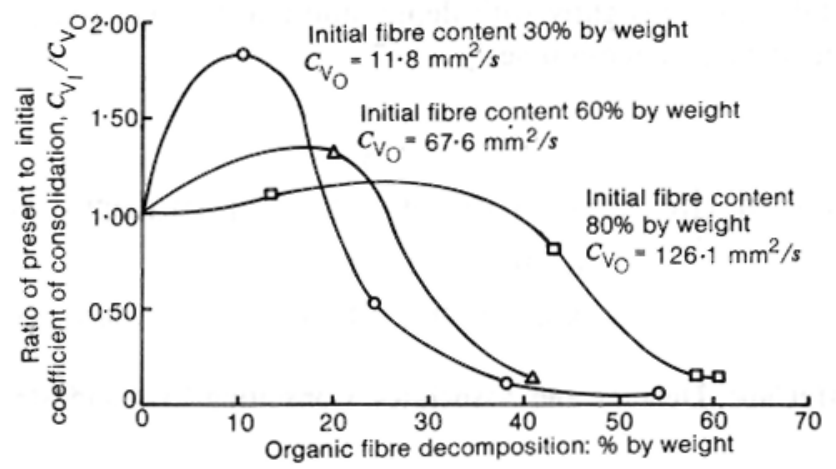

Fig. 1. Change in coefficient of consolidation as a result of organic fibre decomposition (data from Nasif, 1978)

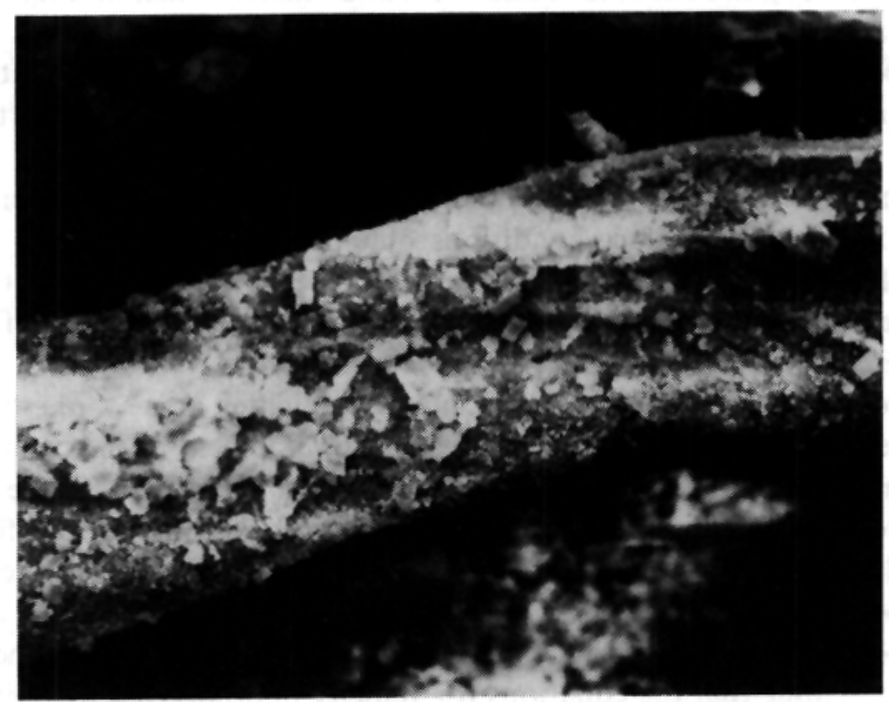

Fig. 2. Partially decomposed cellulose fibre with kaolinite particles, $\times 560$ magnification 
The initial increase in the coefficient of consolidation shown in Fig. 1 may be due to a temporary increase in the equilibrium void ratio caused by the production of $\mathrm{CO}_{2}$ and $\mathrm{CH}_{4}$ during decomposition. This behaviour was most apparent for the samples containing an initial $30 \%$ fibre by weight. Additional decomposition permits lower equilibrium void ratios for the same load increment $\left(23.3\right.$ to $\left.34.9 \mathrm{~g} / \mathrm{cm}^{2}\right)$ which was used for all data points. Changes in $\mathrm{pH}$ due to metabolism of facultative bacteria was countered by adding sodium bicarbonate prior to each consolidation test to give $\mathrm{pH}$ values in the range of 6.8 to 7.4 . These data suggest that decomposition can greatly alter settlement rates for field deposits of organic soils.

\section{REFERENCE}

Nasif, A. A. (1978). Decomposition effects on engineering properties of fibrous organic soils. PhD thesis, Michigan State University, Michigan. Unpublished.

\section{Author's reply}

We were most interested to see the results presented by Andersland and Nasif and are pleased to see that others are thinking along broadly similar lines to ourselves. Preliminary results for our samples suggest that the organic matter content is about $3 \%$, and that the liquidity index is around 1.8 falling only slightly with depth, and that the sensitivity is around 2 . We hope to present further details in due course.

\section{Kinematics of the mass flow of granular matcrial through a plane hopper}

DRESCHER, A., COUSENS, T. W. \& BRANSBY, P. L. (1978). Géotechnique 28, No. 1, 27-42.

\section{Dr R. P. McCabe, McCabe, Delaney and Associates, Consulting Civil and Structural Engineers, Dublin}

The pattern of gravitational flow of granular materials in silos has been investigated by Deutsch and Clyde (1967), McCabe (1971 and 1974) and others. Their findings, while arrived at by different techniques, produced very similar results. The Authors selected a small perspex rectangular hopper to carry out their particular experiments, and arrive at approximately similar results (Fig. 4). A number of matters arise, however, with respect to these experiments.

The radiograph of the hopper (Fig. 2) shows the condition after the surface crater has formed but they do not indicate the surface conditions obtained above crater level when emptying commenced. What interval of time elapsed between the opening of the outlet and descent of the free surface? When, and at what level, would the crater have formed if the hopper had been much deeper?

Secondly, it would be interesting to know how the 'lighter area' took shape in the tests with progressive emptying of the fill, i.e. describe the development of the candle-flame profiles of stress using a rectangular hopper. Was the influence of the corners of the hopper on flow patterns measured? What was the effect of increasing the wall friction on flow patterns?

Thirdly, would the Authors agree that the results of the displacements of their markers (Fig. 3) are inconclusive and are unlikely to give an accurate representation of the facts, having regard for the stop go method used and the presence of corners and flats. In the circumstances, is it reasonable to assume that the equations for velocity jump derived by Shield (1953) apply in this case? After all, any mathematical analysis is only as good as the governing assumption 